\title{
UTILIZAÇÃO DA COMPACTAÇÃO PARA REDUÇÃO DO POTENCIAL DE COLAPSO/ EXPANSÃO DE UM SOLO SILTO ARGILOSO DE MASSAPÊ DA CIDADE DE ICÓ - CE
}

\author{
Use of compression for reducing collapse potential / expansion of a solo \\ clayey silt, Massape city of Icó - CE
}

Gleiber da Silva Chagas ', Alfran Sampaio Moura ${ }^{2}$, Andressa de Araujo Carneiro ${ }^{3}$

Recebido em 14 de abril de 2016; recebido para revisão em 23 de maio de 2016; aceito em 18 de julho de 2016; disponível on-line em 31 de agosto de 2016.

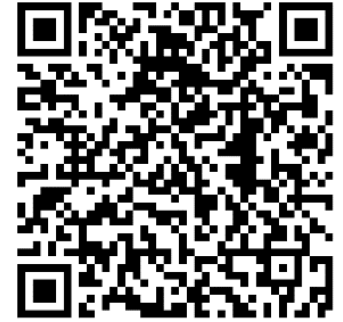

PALAVRAS CHAVE:

Solo colapsível;

Ensaios de campo;

Ensaio edométrico

simples;

Ensaio edométrico duplo;

Ensaio de compactação.

\section{KEYWORDS:}

Collaosible soil;

Field trial;

Simple oedometer

compression test;

Double oedometer

compression test;

Compaction test.
RESUMO: No presente trabalho apresenta-se um estudo do comportamento de um solo silte argiloso, de massapê da cidade de Icó-CE, que será utilizado como suporte das fundações das estruturas de um conjunto habitacional. O objetivo do trabalho é averiguar a eficiência da técnica da compactação na redução do potencial de colapso/expansão do solo estudado. Foi realizada uma caracterização do solo por meio de ensaios de laboratório (granulometria, limite de liquidez, limite de plasticidade, densidade real, compactação e CBR) e campo (SPT). Além disso, realizaram-se ensaios especiais do tipo edométrico simples e duplo. Foram coletadas ainda, em uma empresa local, um total de 20 furos de sondagens à percussão (SPT) e que foram realizadas no local do estudo. Pela análise dos resultados foi possível verificar que a compactação mostrou-se uma técnica eficiente para minorar ou mesmo eliminar o potencial de expansão/colapso do solo estudado. A realização deste trabalho contribui para a área do conhecimento pois comprova, a partir do estudo de um caso real, que a compactação de solos potencialmente colapsíveis ou expansivos, de fato, reduz seu potencial a níveis aceitáveis para uso como suporte de fundações superficiais de edifícios.

ABSTRACT: FIn this paper we present a study of the behavior of a clayey silt soil, the city massapê Icó-CE, which will be used to support the foundations of the structures of a housing development. The objective is to ascertain the efficiency of the technique of compression in reducing the potential for collapse / expansion of the studied soil. A characterization of the ground by means of laboratory tests (grain size, liquid limit, plastic limit, real density, compaction and CBR) and field (SPT). In addition, there were special tests of simple and double edometer type. Were also collected, in one place, a total of 20 percussion boreholes (SPT) and were performed at the study site company. By analyzing the results we observed that compaction proved to be an efficient technique to reduce or even reduce the potential for expansion / collapse of the studied soil. This work contributes to the field of knowledge as proof, from the study of a real case that the compression of potentially collapsible or expansive soils, in fact, reduces its potential to acceptable levels for use as support shallow foundations of buildings.

\footnotetext{
* Contato com os autores:

1 e-mail: gleiberchagas@unifor.br (G. S. Chagas)

Geólogo, Mestre em Engenharia Civil-Geotecnia, Professor da Universidade de Fortaleza (UNIFOR).

2e-mail: alfransampaio@ufc.br (A.S. Moura)

Eng. Civil, Doutor, Professor do Departamento de Engenharia Hidráulica e Ambiental da Universidade Federal do Ceará (UFC).

${ }^{3}$ e-mail: andressa@ufpi.edu.br (A. A. Carneiro)

Geóloga, Mestra, Professora do Dep. de Rec. Hídricos, Geotecnia e Saneamento Ambiental da Universidade Federal do Piauí (UFPI).
} 


\section{INTRODUÇÃO}

De acordo com a literatura geotécnica, os solos colapsíveis ocorrem em várias partes do Brasil e de outros países. Solos colapsíveis tem sido muitas vezes, causadores de sérios danos ocorridos em edifícios, barragens e diversos outros tipos de obras. Decorre destes fatos, a importância em se detectar a presença desse tipo de solo e analisar o seu comportamento frente aos agentes que desestabilizam a sua estrutura, tais como a intensidade da carga atuante do liquido inundante (AGNELLI e ALBIERO, 1997).

De acordo com Diniz e Santoro (2004), alguns solos apresentam comportamento característico sobre determinadas condições de umidade, dentre eles, destacam-se os solos colapsíveis. Esses solos, ao serem inundados e estando sob a ação de sobrecarga, sofrem uma brusca e significativa redução de volume.

Segundo Vilar, Machado e Bueno (1998), os solos potencialmente colapsíveis apresentam como característica a estrutura macroscópica fofa, baixo grau de saturação e partículas maiores mantidas por cimentação ou por tensão capilar.

Os solos colapsíveis no Brasil estão associados a solos de diferentes formações aluviais, coluviais e residuais, sendo mais frequentes na região Centro-Sul e Nordeste. Os solos colapsíveis são caracterizados por uma estrutura altamente porosa em que as partículas sólidas se mantêm interligadas por meio de vínculos que possuem uma resistência temporária proveniente de forças capilares ou de adsorção, ou pela presença de algum agente cimentante.

O Quadro 1 mostra diversos locais onde foram identificados solos colapsíveis no Nordeste.

De acordo com Moura et al. (2011), os solos não saturados são de natureza bastante diversa. Dentro dessa categoria estão as argilas expansivas altamente plásticas, solos residuais lateríticos e saprolíticos, além de uma grande variedade de depósitos aluvionares, coluvionares e eólicos, diferentes tipos de solos compactados e cimentados.

Os solos não saturados são aqueles em que os poros não estão completamente cheios de líquidos (normalmente a água) havendo também a presença de gases (normalmente o ar).

Quando submetidos a variações de umidade, principalmente, por condições climáticas, esses solos apresentam mudanças de resistência ao cisalhamento e instabilidade volumétrica, originando fenômenos como colapso e expansão.

QUADRO 1: Ocorrências de solos colapsíveis no Nordeste.

\begin{tabular}{|l|c|c|}
\hline Local & Referência & Origem dos Solos / Classe Pedológica \\
\hline Parnaíba - PI & Riani e Barbara (1989) & Eólica / Areia quartzosa \\
\hline Natal - RN & Santos Junior e Araújo (1999) & Fólico / Areia Quartzosa \\
\hline Recife - PE & Ferreira (1997) & $\begin{array}{c}\text { Complexo Carnaíba Remobilizado / } \\
\text { Podzólico }\end{array}$ \\
\hline Gravatá - PE & Ferreira (1989) & Compelxo Moteiro / Bruno não cálcico \\
\hline Carnaíba - PE & Ferreira (1989) & Formação Tacaratu / Areia quartzosa \\
\hline Petrolândia - PE & Ferreira (1989) & Aluvial / Areia quartzosa \\
\hline $\begin{array}{l}\text { Sta Maria da Boa Vista } \\
\text { - PE }\end{array}$ & Ferreira (1989) & Formação Marizal / Areia quartzosa \\
\hline Petrolina - PE & Aragão e Melo (1982) & Ferreira (1989) \\
\hline Rodelas - BA & Ferreira (1989) & Formação Vazante e Aluviões / Latossolos e Areias \\
\hline Bom Jesus da Lapa - BA & Mendonça (1990) & \\
\hline
\end{tabular}


Os solos expansivos são os solos coesivos que aumentam de volume quando umedecidos e se contraem quando ressecam. As características dos solos potencialmente expansivos são: solos não saturados, presença de argilo-minerais expansivos (especialmente as montmorilonitas), solos derivados de rochas ígneas (basaltos, diabásios e gabros) e de rochas sedimentares (folhelhos e calcários).

Geralmente a ocorrência de solos colapsíveis está relacionada a locais com deficiência hídrica, em regiões de baixos níveis de precipitações pluviométricas, embora tenha havido a constatação desses tipos de solos em outras regiões de maior pluviosidade.

Os solos expansivos, no Brasil, são encontrados em várias regiões do país, o Quadro 2 mostra alguns exemplos da ocorrência desse tipo de solo.

Solos compactados que apresentam colapso tem tipicamente um tipo de estrutura com muitos espaços vazios, que possibilitam a formação de uma estrutura meta estável. Muitos pesquisadores apresentam propostas relativas ao arranjo estrutural das partículas destes solos. Estas postulações tem em comum a descrição da estrutura do solo que fixa que o volume de grãos é mantido junto numa forma de estrutura de colmeia de abelhas através de um tipo de material ligante ou força nos pontos de contato. Os diversos arranjos estruturais postulados diferem com respeito ao tamanho e orientação do material ligante.

De acordo com Ferreira (2005), a ocorrência de solos potencialmente colapsíveis é favorecida por: estrutura porosa potencialmente instável; solo não saturado; presença de agentes cimentantes; e instabilidade com tensão externa aplicada. Os fatores que influenciam a colapsividade dos solos são: estrutura, peso específico aparente seco, umidade, tipo de permeante, mineral argílico, velocidade de inundação, tensão vertical de inundação, trajetória de tensões, etc.

Os métodos de identificação de argilas potencialmente expansivas podem ser classificados em indiretos e diretos. Os métodos indiretos são baseados na classificação mineralógica, índices físicos, limites de consistência e parâmetros associados à textura e composição da argila. Já os métodos diretos são baseados a medida de expansão induzida ao solo (SILVA, 2005).

Segundo Cintra (1998), em diversas obras em que utilizaram a técnica da compactação, solos anteriormente colapsiveis apresentaram menor compressibilidade e colapsibilidade.

Os problemas em fundações superficiais que envolvem o solo, de acordo com Milititsky et al. (2008) podem ocorrer na construção de obras onde ocorrem cortes e aterros, mas com fundações construídas na mesma cota de forma que os elementos de fundação fiquem assentes em solos de diferentes comportamentos, resultando em recalques diferenciais importantes ou mesmo o colapso das fundações.

Ricardo e Catalani (2007) recomendam que para a utilização de aterros como fundação é necessário que estes aterros apresentem um grau de compactação de $90 \%$ a $95 \%$ do Proctor modificado ou $95 \%$ a $100 \%$ do Proctor normal.

\begin{tabular}{|l|c|c|}
\hline \multicolumn{2}{|c|}{ Quadro 2: Exemplos de ocorrências de solos expansivos no Brasil. } \\
\hline Local & Referência & Origem / Solo / Classe Pedológica \\
\hline Paulo Dutra - MA & Ferreira (1988) & - \\
\hline Parelhas - RN & Lins et al. (1986) & Formação Seridó \\
\hline Carnaíba - PE & Ferreira (1988) & Complexo Monteiro / Bruno não cálcico \\
\hline Salvador - Feira de Santana - BA & Presa (1986) & Solos residuais / Vertissolo \\
\hline Campinas - SP & Samara (1981) & Podzólico \\
\hline Porto alegre - RS & Vargas et al. (1989) & Formação Rosário do Sul \\
\hline
\end{tabular}




\section{OBJETIVO}

O objetivo desse trabalho é avaliar, a partir de um caso real, se a compactação é um procedimento capaz de eliminar o potencial de colapso de um solo silte argiloso do Município de Icó, Ceará, em área destinada à construção de conjunto residencial.

\section{REVISÃO BIBLIOGRÁFICA}

Solos colapsíveis são solos não saturados que experimentam um rearranjo radial de partículas seguido de uma redução de volume quando inundado com acréscimo ou não de sobrecarga. (CLEMENCE e FINBARR, 1981).

Os processos de escavação, de remoldagem e de recompactação resultam em um material não saturado. Os solos compactados são solos naturais em que suas condições iniciais são modificadas para melhorar o comportamento mecânico e sua utilização em obras em terra. O solo é considerado não saturado quando há presença de ar nos vazios, mesmo em pequena quantidade.

Outra definição para solos colapsíveis, como a de Reginatto e Ferrero (1973), considera dois tipos existentes: os solos verdadeiramente colapsíveis, que não suportam o seu próprio peso quando inundados e colapsam; e os solos condicionados ao colapso, sendo aqueles cuja ocorrência do colapso é função do nível de tensões a que o solo está submetido.

De acordo com Ferreira (2005), a ocorrência de solos colapsíveis é favorecida por: estrutura porosa potencialmente instável; solo não saturado; presença de agentes cimentantes; e instabilidade com tensão externa aplicada. Os fatores que influenciam a colapsividade dos solos são: estrutura, peso específico aparente seco, umidade, tipo de permeante, mineral argílico, velocidade de inundação, tensão vertical de inundação, trajetória de tensões, etc.

Os solos colapsíveis são caracterizados por uma estrutura altamente porosa em que as partículas sólidas se mantêm interligadas por meio de vínculos que possuem uma resistência temporária proveniente de forças capilares ou de adsorção, ou pela presença de algum agente cimentante.

O colapso se dá pela ação de algum agente externo que causa o enfraquecimento da estrutura e provoca o deslizamento das partículas, resultando em um rearranjo da estrutura do solo, com a consequente redução de volume (GOMES, 2006).

A colapsividade dos solos pode ser estudada através dos ensaios de compressão edométrica.

Segundo Pinto (2006), os ensaios edométricos representam adequadamente as condições do terreno abaixo de fundações superficiais, tendo como vantagem seu baixo custo quando comparado a outras técnicas utilizadas para previsão de recalques. Os ensaios de compressão edométrica podem ser simples ou duplos.

Segundo Gomes (2006), o ensaio de compressão edométrica simples para o corpo de prova na umidade natural, deve ser realizado de maneira convencional até a tensão em estudo (25 kPa). Depois de estabilizadas as deformações, o corpo de prova deverá ser saturado, para então serem observadas as deformações decorrentes dessa saturação. Já o ensaio de compressão edométrica duplo é realizado com a execução simultânea de dois corpos de prova, um no estado natural e outro saturado. A previsão dos recalques é calculada de acordo com a teoria do adensamento.

Segundo Silva (2005), as mudanças de volume podem ser resultantes de fatores como clima, construção, vegetação, irrigação, cobertura da área, dentre outros. Um solo potencialmente expansivo é aquele que apresenta aumento ou contração de volume quando sofre variação na umidade ou na sucção, por ser constituído por minerais expansivos.

A compactação de um solo é qualquer redução, mais ou menos rápida, do índice de vazios, por processos mecânicos. Essa redução ocorre pela expulsão ou compressão do ar dos vazios dos poros. O objetivo da compactação do solo é conferir a este uma homogeneização e melhoria de suas características de engenharia, tais como: aumentar a resistência ao cisalhamento, reduzir os recalques e aumentar a resistência à erosão (MASSAD, 2010). 
O processo de compactação de um solo pode ser subdividido em etapas, visando aplicar maior esforço para levar o material às condições exigidas pelo projeto ou norma técnica, com a finalidade principal de conformar a superfície compactada.

Os fatores que influem na compactação de campo são: teor de umidade do solo, número de passadas do equipamento, espessura da camada compactada e características do equipamento (pressão, área de contato, etc.).

Não sendo atingida a compactação desejada, a qual não deverá ser inferior a determinado valor do grau de compactação (fixada pela especificação adotada), o material deverá ser removido e recompactado (DNIT, 2006).

Argilas compactadas no ramo seco da curva de compactação desenvolvem um arranjo de partículas que não exibe influência marcante do tipo de compactação empregado, ao passo que, quando compactadas no ramo úmido, são significativamente afetadas a orientação das partículas, a resistência, a permeabilidade e a compressibilidade das argilas (CERNICA, 1995).

De acordo com Milititsky et al. (2008), as causas de recalques em fundações assentes em aterros podem ser de três tipos:

I. Devido ao peso próprio ou pela transferência de carga da superestrutura;

II. Deformações do solo natural localizado abaixo do aterro;

III. Degradação da matéria orgânica de aterros sanitários desativados.

Os problemas em fundações superficiais que envolvem 0 solo, de acordo com Milititsky et al. (2008) podem ocorrer na construção de obras onde ocorrem cortes e aterros, mas com fundações construídas na mesma cota, de forma que os elementos de fundação fiquem assentes em solos de diferentes comportamentos, resultando em recalques diferenciais importantes ou mesmo o colapso das fundações.

Outro problema de fundações superficiais envolvendo o solo é a sobre-escavação preliminar e reaterros mal executados. Esse procedimento resulta em sapatas apoiadas em condições diferentes das estimadas em decorrência das características precárias do material sem os cuidados necessários de compactação, o que resulta na ocorrência de recalques (MILITITSKY et al., 2008).

A substituição de solo com uso de material não apropriado ou executado sem compactação adequada é também um problema frequente em fundações superficiais, que pode causar instabilidade da fundação.

Ricardo e Catalani (2007) recomendam que para a utilização de aterros como fundação é necessário que estes aterros apresentem um grau de compactação de $90 \%$ a $95 \%$ do Proctor modificado ou $95 \%$ a $100 \%$ do Proctor normal.

\section{METODOLOGIA}

A metodologia adotada para a realização deste trabalho foi baseada na realização das seguintes etapas:

- Definição da área estudada e caracterização do meio físico;

- Coleta de dados;

- Coleta de amostras deformada e indeformadas;

- Caracterização geotécnica;

- Realização de ensaios edométricos em amostras indeformadas e compactadas;

- Apresentação dos resultados e análises.

- A seguir apresentam-se em itens específicos as informações relativas a cada uma das etapas mencionadas.

\subsection{DEFINIÇÃO DA ÁREA ESTUDADA $E$ CARACTERIZAÇÃO DO MEIO FÍSICO}

O local da área para a realização do presente estudo está localizado no interior do estado do Ceará, mais precisamente na cidade de Icó. O município de Icó está localizado na região sudeste do estado do Ceará, abrangendo uma área total de $1.871,98 \mathrm{Km}^{2}$, distante da capital Fortaleza $301 \mathrm{Km}$.

No município de Icó ocorrem três domínios hidrogeológicos distintos: formações sedimentares, embasamento cristalino e depósitos aluvionares. As formações sedimentares estão agrupadas em um contexto maior e constituem a Bacia Sedimentar do Iguatu (CPRM, 2004). 
A Bacia Sedimentar de Iguatu está dentro de um contexto sedimentar representado por três sistemas aquíferos principais: Icó, Malhada Vermelha e Lima Campos. Além desses, existem outros três sistemas aquíferos sedimentares: Moura, Coberturas Recentes e Aluviões (CPRM, 2004).

$\mathrm{Na}$ Bacia de Iguatu ocorrem em uma larga faixa localizada na porção centro-oeste, estreitando-se em direção à borda sul-sudeste uma formação denominada coberturas colúvio-eluviais. Distribui-se também no centro da Bacia de Icó, no sudoeste e na sua extremidade nordeste. As coberturas colúvio-eluviais correspondem a depósitos continentais semiconsolidados a inconsolidados, constituídos de mátria areno-argilosa, com grãos de quartzo e concreções ferruginosas avermelhadas (CPRM, 2004).

Os depósitos aluvionares são representados por sedimentos areno-argilosos recentes, que ocorrem margeando as calhas do principal rio do estado, rio Jaguaribe e riachos que drenam a região. As rochas cristalinas ocupam pequena porção ao sul do município e representam o que é denominado comumente de "aquífero fissural".

A coluna estratigráfica da área de estudo engloba, da base para o topo, as seguintes formações: Icó, Malhada Vermelha e Lima Campos, constituintes do Grupo Iguatu. Essas unidades apresentam-se sotopostas discordantemente aos

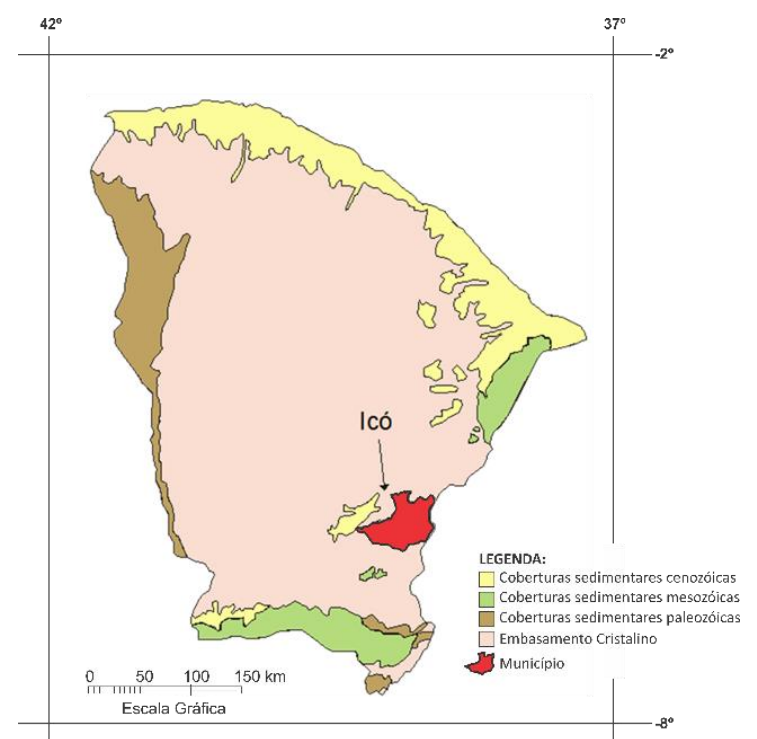

FIGURA 1. Localização do município de Icó em relação aos domínios sedimentares e cristalino do estado do Ceará.

FONTE: CPRM (1998). depósitos Tércio-Quaternários da Formação Moura e das coberturas Colúvio-eluviais, além das aluviões. (CPRM, 2004).

A Bacia de Icó (Figura 1), situada na região sudeste do Estado do Ceará, representa uma das várias ocorrências de sedimentos cretáceos continentais do Nordeste do Brasil. Esta Bacia é representada por uma faixa sedimentar de direção SW-NE, possui cerca de $50 \mathrm{~km}$ de comprimento por $8,0 \mathrm{~km}$ de largura máxima (CPRM, 2004). Analisando-se os perfis da Figura 2, verifica-se a coincidência do NSPT até a profundidade de 2,0 $\mathrm{m}$, a partir daí, a sondagem SP-01 apresentou valores do NSPT mais elevados que os obtidos na sondagem SP-15, e ambos, a partir de $6,0 \mathrm{~m}$ de profundidade apresentam-se impenetráveis à percussão.

O local específico do presente estudo corresponde a um terreno situado às margens da rodovia BR 404, onde seria construído um condomínio residencial de 3 pavimentos. Os edifícios do mencionado condomínio serão construídos em fundações superficial do tipo sapata por exigência contratual. Ocorre que, superficialmente, há uma camada de solo silto argiloso, que apresenta visualmente indícios de solo problemático, como pode ser observado na Figura 2. Dessa forma, a presença desse possível solo problemático que receberá as fundações superficiais de um edifício motivou a realização desse trabalho.

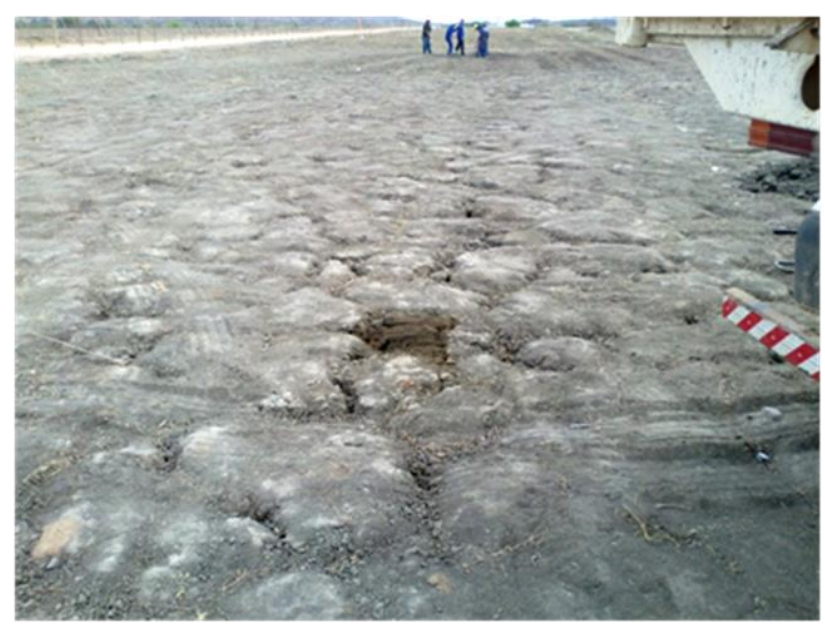

FIGURA 2. Vista do solo superficial. FONTE: Autoria própria. 


\subsection{COLETA DE DADOS}

Inicialmente foram coletadas, em uma empresa de geotecnia local, um total de 20 furos de sondagens à percussão (SPT), que já tinham sido executados anteriormente ao início desta pesquisa, e que estavam posicionados ao longo do perímetro da futura obra. Para o presente estudo, foram selecionadas apenas as 2 sondagens (SP-01 e SP-15) situadas mais próximas dos locais que seriam obtidas amostras do solo para a realização de ensaios de laboratório, que serão descritos a seguir. Vale registrar que todas as sondagens foram realizadas no mês de julho, que é um mês com escassa ocorrência de chuvas.

No Furo SP-01 (Figura 3) não atingiu-se o N.A. Até a profundidade de $0,5 \mathrm{~m}$ foi observado a presença de pedregulhos (seixo rolado), de 1,0 $\mathrm{m}$ a 4,0 m tem-se um silte argiloso de consistência média, e abaixo deste, um silte arenoso, muito compacto, de cor cinza esverdeada e amarela até a profundidade de $6,63 \mathrm{~m}$, em que o solo apresentouse impenetrável à percussão.

Já no furo SP-15, o N.A também não foi encontrado. Neste caso, obteve-se que o subsolo é composto por uma camada superficial de areia fina a média, siltosa, pouco compacta até $2,20 \mathrm{~m}$, seguida de um silte argiloso até $2,70 \mathrm{~m}$ e, abaixo deste, um silte arenoso, pouco argiloso, muito compacto até $6,20 \mathrm{~m}$.

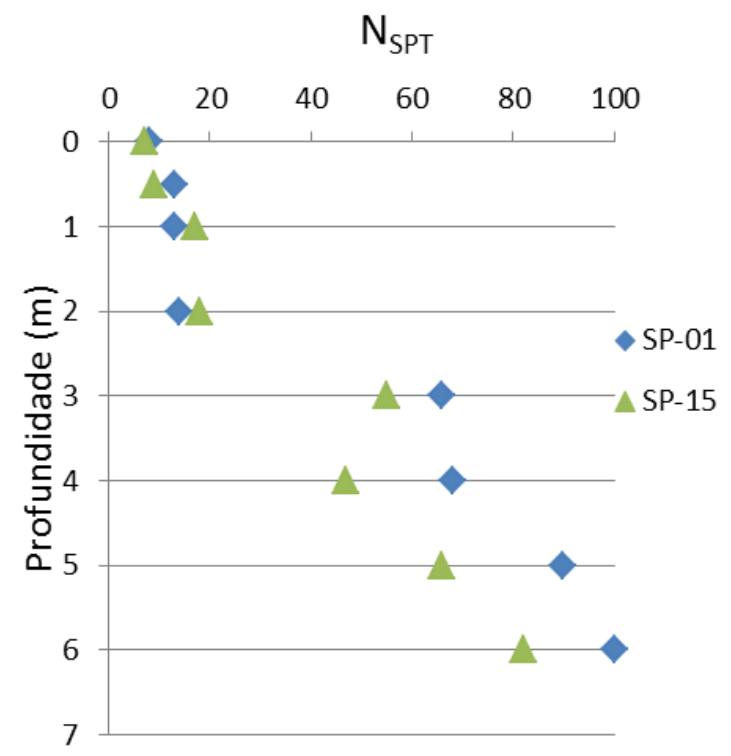

FIGURA 3. Comparação dos perfis de resistência dos furos SP-01 e SP-15.

FONTE: Autoria própria.
Analisando-se os perfis da Figura 3, verifica-se a coincidência do NSPT até a profundidade de $2,0 \mathrm{~m}$, a partir daí, a sondagem SP-01 apresentou valores do NSPT mais elevados que os obtidos na sondagem SP-15, e ambos, a partir de 6,0 m de profundidade apresentam-se impenetráveis à percussão.

\subsection{COLETA DE AMOSTRAS}

Para a execução dos ensaios de caracterização e compactação foram coletadas amostra de solo deformada e para a execução de ensaios edométricos coletaram-se amostras indeformadas.

A Figura 4 ilustra a localização da coleta de amostras deformadas e indeformadas.

A amostra deformada foi obtida pela coleta de solo após remoção de uma camada superficial de matéria orgânica com pedregulhos, utilizando-se de pá e picareta. Já as coletas das amostras indeformadas foram realizadas com auxílio de uma retro-escavadeira, a partir da escavação de uma vala de aproximadamente $1,0 \mathrm{~m}$ de comprimento, $1,0 \mathrm{~m}$ de largura e $1,0 \mathrm{~m}$ de profundidade. A obtenção do bloco indeformado, foi realizada abaixo desta profundidade e, a amostra foi envolta em parafina, para preservação da umidade de campo e devidamente encaixotada, sendo transportada em seguida até o laboratório cujos ensaios foram realizados. Vale mencionar que todos os procedimentos realizados para a obtenção das amostras deformada e indeformadas seguiram criteriosamente todas as recomendações das normas pertinentes.

\subsection{CARACTERIZAÇÃO GEOTÉCNICA}

A caracterização geotécnica foi feita a partir da realização de ensaios de granulometria, índices de consistência e densidade real. Além desses, visando obter informações para a moldagem dos corpos de prova compactados, foram realizados ainda ensaios de compactação (Próctor Normal), e Índice de Suporte Califórnia (ISC). Por fim realizaram-se ainda, em campo, ensaios de frasco de areia e para a determinação da umidade de campo. Vale mencionar que, 
novamente, todos os ensaios realizados seguiram rigorosamente as Normas Brasileiras pertinentes

A Tabela 1 apresenta os resultados dos ensaios de caracterização geotécnica, compactação e ISC realizados a partir das amostras deformadas coletadas.
De acordo com a classificação do Highway Research Board (AASHTO, 1982), a amostra estudada enquadra-se no subgrupo dos solos A-6 e corresponde a um silte argiloso.

A Figura 5 mostra a curva granulométrica da amostra de solo em estudo.

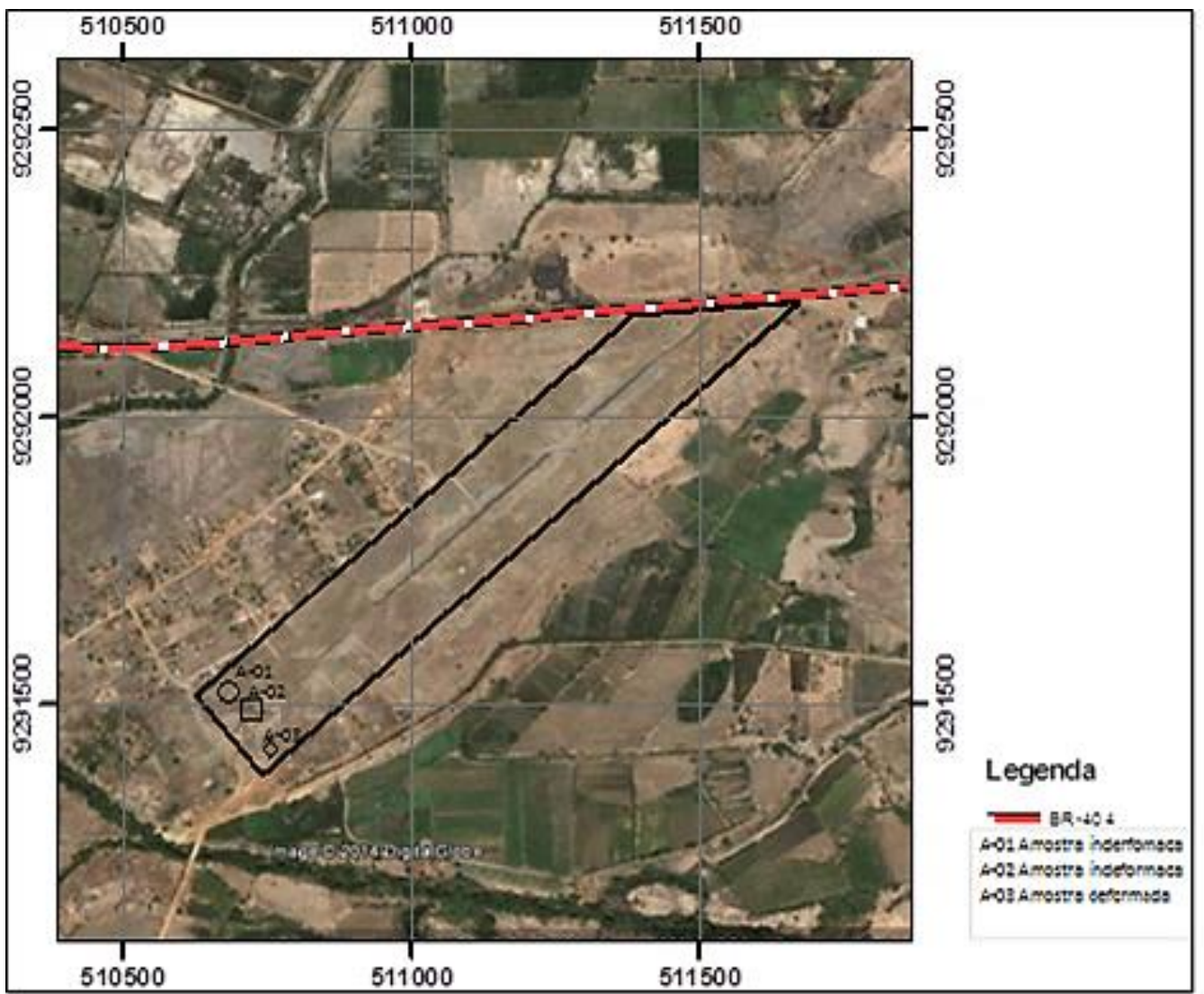

FIGURA 4. Localização da coleta de amostras deformadas e indeformadas. FONTE: Autoria própria.

\begin{tabular}{|c|c|c|c|c|c|c|c|c|c|}
\hline \multicolumn{8}{|c|}{ TABELA 1:. Resultados dos ensaios de laboratório realizados caracterização e compactação). } \\
\hline \multicolumn{3}{|c|}{$\begin{array}{c}\text { Granulometria } \\
\text { (\% passando) }\end{array}$} & \multicolumn{2}{c|}{ Limites Físicos } & $\begin{array}{c}\text { Compactação } \\
\text { (12 golpes) }\end{array}$ & ISC & Expansão \\
\hline$\# 4$ & $\# 10$ & $\# 40$ & $\# 200$ & LL & LP & Wot (\%) & $\begin{array}{c}\gamma \mathrm{dmax} \\
\left(\mathrm{kN} / \mathrm{m}^{3}\right)\end{array}$ & $\%$ & $\%$ \\
\hline 100 & 95 & 97 & 86 & 40 & 11 & 15,3 & 16,7 & 3 & 5 \\
\hline
\end{tabular}

FONTE : Autoria própria.

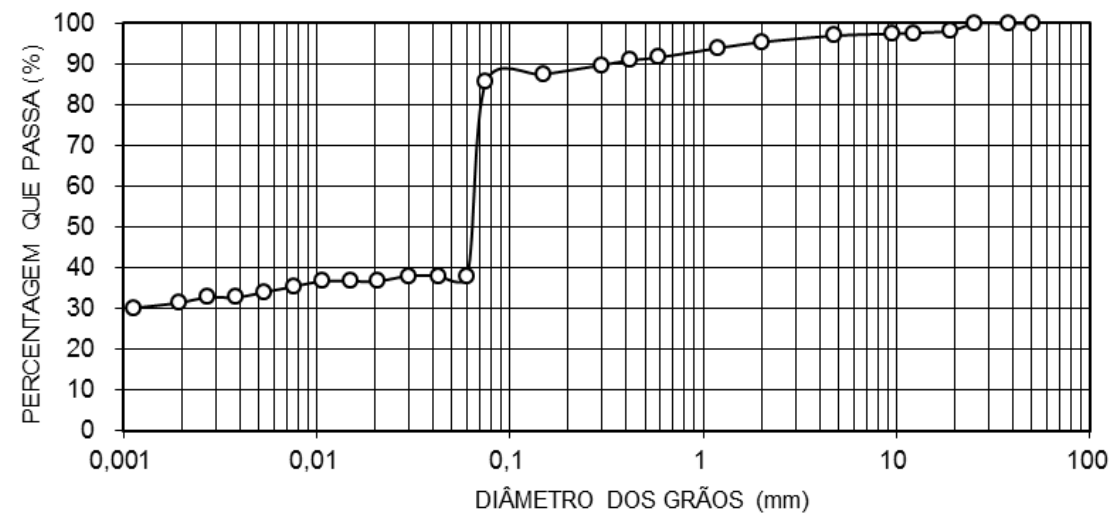

FIGURA 5: Curva granulométrica para o solo em estudo. FONTE: Autoria própria. 
Por meio da Figura 5 observa-se que tratase de um solo predominantemente fino com cerca de $86 \%$ passando na peneira de número 200 , apresentando $14 \%$ de areia, $51 \%$ de silte e $35 \%$ de argila.

Já a partir do ensaio de frasco de areia obteve-se um peso específico de campo de $18,8 \mathrm{kN} / \mathrm{m}^{3}$ e uma umidade natural de $8 \%$.

\subsection{ENSAIOS EDOMÉTRICOS EM AMOSTRAS INDEFORMADAS E COMPACTADAS}

Para identificar o provável comportamento colapsível do solo avaliado e o seu potencial, realizaram-se ensaios de adensamento simples e duplo, realizados em corpos de prova inderformados. Por não existir Norma específica, tomou-se como referencial os procedimentos básicos do ensaio de adensamento estabelecidos pela Norma MB-3336 (ABNT, 1990).

O ensaio oedométrico duplo consistiu em utilizar dois corpos de prova, um na umidade natural e outro inundado. $O$ ensaio tem por objetivo determinar as diferenças entre o índice de vazios (e) do solo natural e inundado quando submetidos a iguais valores de tensões de compressão.

No ensaio dois corpos de prova foram submetidos a estágios de tensão de compressão até estabilização das deformações. Um dos corpos de prova foi inundado na tensão de projeto $(25 \mathrm{kPa})$, enquanto o outro foi mantido na umidade natural durante todos os estágios de carga. Os estágios de pressão aplicados foram os seguintes: $13 \mathrm{kPa}$; $25 \mathrm{kPa} ; 50 \mathrm{kPa} ; 100 \mathrm{kPa} ; 200 \mathrm{kPa} ; 400 \mathrm{kPa}$ e $800 \mathrm{kPa}$.

A partir dos resultados dos ensaios puderam-se construir um gráfico relacionando $o$

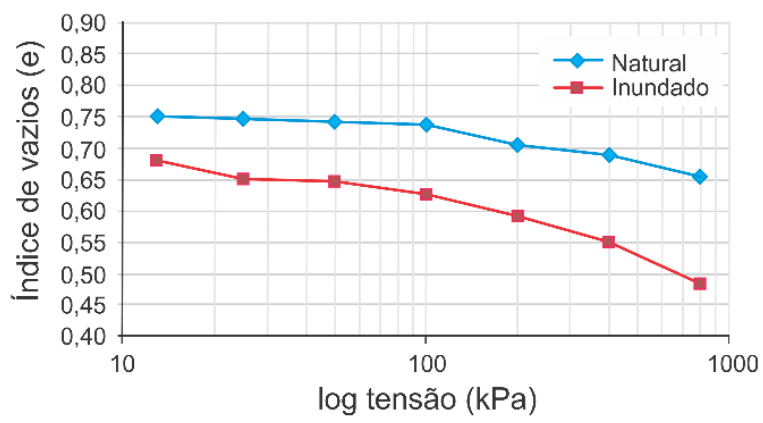

FIGURA 6: Gráfico e $x \sigma_{v}$ do ensaio edométrico duplo comparativo do trecho de carregamento para os corpos de prova a umidade natural e inundado.

FONTE: Autoria própria. índice de vazios (e) com o logaritmo das tensões aplicadas $\left(\log \sigma_{\mathrm{v}}\right)$.

A Figura 6 mostra os resultados do ensaio edométrico duplo, realizado em um corpo de prova na condição natural.

Posteriormente, realizaram-se também ensaios edométrico simples. Neste ensaio, o corpo de prova no estado natural foi submetido normalmente ao $1^{\circ}$ e ao $2^{\circ}$ estágio de tensão. Após a estabilização das deformações do 20 estágio, que corresponde a tensão de $25 \mathrm{kPa}$ (tensão de projeto), foi realizada a inundação da amostra e esperada, novamente, a estabilização das deformações. Em seguida procedeu-se o ensaio da maneira convencional aplicando-se incrementos de pressão correspondestes a cada estágio de carga. As cargas aplicadas foram de $13 \mathrm{kPa}, 25 \mathrm{kPa}, 50 \mathrm{kPa}$, $100 \mathrm{kPa}, 200 \mathrm{kPa}, 400 \mathrm{kPa}$ e $800 \mathrm{kPa}$.

Na Figura 7 apresentam-se os resultados do ensaio edométrico simples realizado em um corpo de prova na condição natural.

Posteriormente, para verificar o efeito da compactação no potencial de colapso/expansão do solo realizaram-se ensaios de adensamento simples e duplo em corpos de prova compactados. Os ensaios foram realizados a partir dos mesmos procedimentos executados nos corpos de prova indeformados. Neste caso, os corpos de prova foram moldados na umidade ótima $\left(w_{o t}\right)$ e peso específico aparente seco máximo $\left(\gamma_{\mathrm{dmax}}\right)$, de acordo com ensaio de compactação com energia de compactação Próctor Normal.

Os gráficos das Figuras 8 e 9 apresentam os resultados obtidos com os ensaios de adensamento simples e duplo, realizados em corpos de prova compactados.

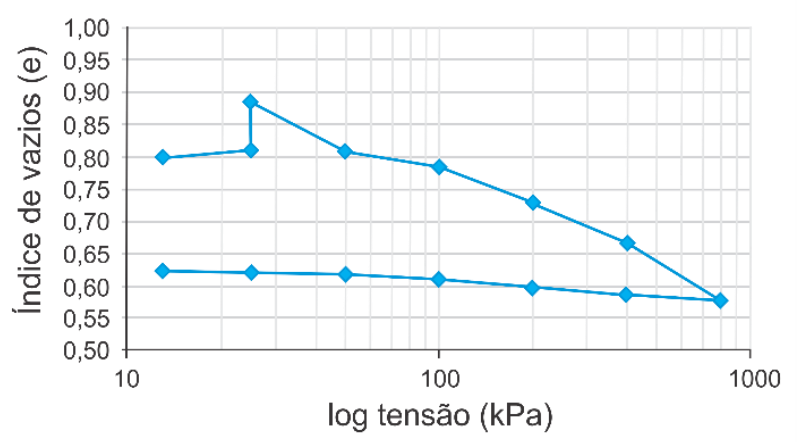

FIGURA 7: Adensamento simples para amostra de solo indeformado.

FONTE: Autoria própria. 


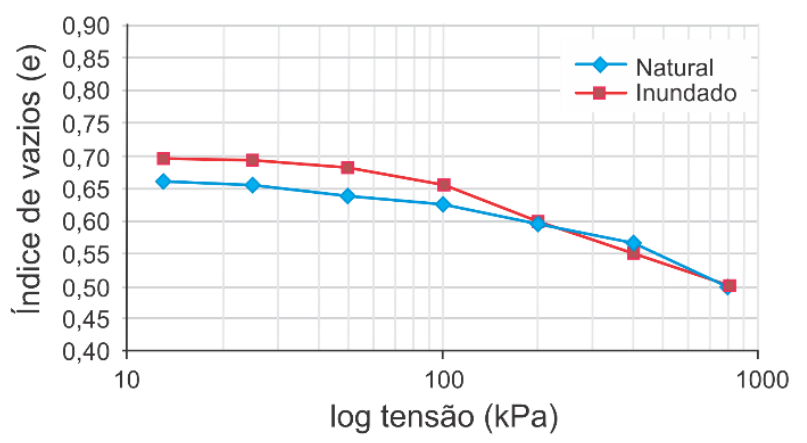

FIGURA 8: Adensamento duplo para amostra compactada.

FONTE: Autoria própria.

\section{RESULTADOS}

A partir dos resultados dos ensaios de caracterização já foi possível prever, preliminarmente, que o solo estudado tratava-se de um solo com potencial de expansão. Inicialmente, utilizou-se a proposta de Skempton (1953) que propõe a relação entre a atividade do solo e seu potencial de expansão.

Dessa forma, a atividade do solo amostrado a partir da Equação 1:

$$
A=\frac{I P}{\%<0,002 m m}
$$

Sendo:

A : índice de atividade;

IP : índice de plasticidade;

$\%<0,002 \mathrm{~mm}$ : fração de argila (menor que $0,002 \mathrm{~mm})$.

A atividade do solo ensaiado foi estimada em 1,26, que de acordo com Pinto (2006), corresponde a uma argila ativa. Segundo Nelson e Miller (1992), argilas ativas apresentam um maior potencial para a expansão. Esse resultado justifica a expansão obtida no corpo de prova natural submetido ao ensaio edométrico simples, conforme pode ser observado na Figura 7.

Já em função do teor de finos, que neste caso é de $32 \%$, há uma probabilidade de colapso inferior a $50 \%$.

Com relação aos ensaios edométricos, inicialmente será comentado o resultado do ensaio edométrico duplo, realizados em corpo de prova na condição natural. Posteriormente, esses resultados serão comparados com os resultados obtidos a

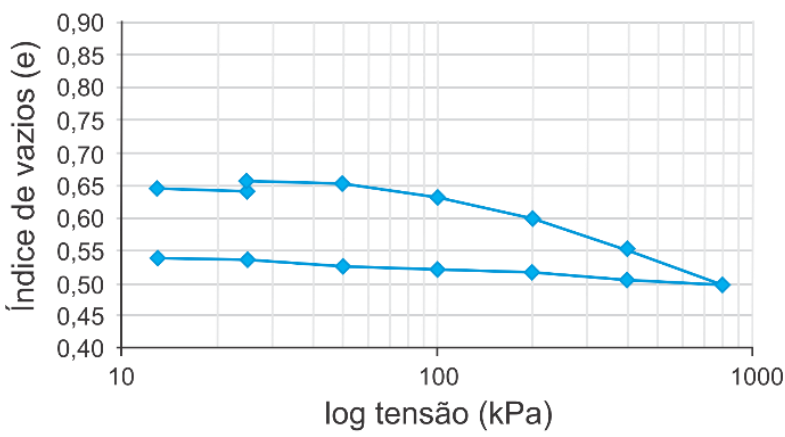

FIGURA 9: Adensamento simples para amostra compactada.

FONTE: Autoria própria.

partir de um corpo de prova compactado e submetido ao mesmo ensaio. Posteriormente, os resultados do ensaio edométrico simples realizado no corpo de prova na condição natural serão comparados com os resultados obtidos a partir do corpo de prova compactado e submetido ao mesmo ensaio.

Com relação aos corpos de prova ensaiados na condição natural, a partir do ensaio edométrico duplo (Figura 6), observa-se um distanciamento considerável entre as curvas correspondentes ao solo natural e inundado, indicando tratar-se de um solo possivelmente colapsível.

De acordo com Reginatto e Ferrero (1973), pode-se determinar o potencial de colapso a partir da Equação 2:

$$
C=\frac{\sigma_{v p s}-\sigma_{v_{0}}}{\sigma_{v p n}-\sigma_{v 0}}
$$

Sendo:

$\sigma_{\text {vpn }}$ : é a tensão de pré adensamento virtual do solo na umidade natural;

$\sigma_{v p s}$ : é a tensão de pré adensamento virtual do solo inundado;

$\sigma_{\mathrm{vo}}$ : é a tensão vertical devido ao peso próprio do solo em campo.

Estimou-se então o potencial de colapso em $0,21 \%$, calculado a partir de dados obtidos na Figura 4, onde $\sigma_{\mathrm{vpn}}=200 \mathrm{kPa}, \sigma_{\mathrm{vps}}=50 \mathrm{kPa}$ e $\sigma_{\mathrm{vo}}=10$ $\mathrm{kPa}$. Dessa forma, a partir do ensaio edométrico duplo, conclui-se que o solo trata-se de um solo "condicionado ao colapso".

Por meio do gráfico da Figura 8, observa-se que a curva de adensamento correspondente ao solo inundado pois posicionou- 
se ligeiramente acima da curva do solo natural, indicando que o processo de compactação realmente anulou o potencial de colapso do mesmo, demonstrando que a compactação mostrou-se um processo eficaz para o tratamento do solo estudado.

Com relação à curva edométrica do ensaio simples relativa ao corpo de prova no estado natural, observa-se pelo gráfico da Figura 7 que, ao contrário da tendência mostrada na Figura 6 , houve uma expansão do corpo de prova com a saturação. Neste caso na pressão de $25 \mathrm{kPa}$, obteve-se altura inicial do corpo de prova igual a $25,7 \mathrm{~mm}$, e após saturada a altura atingiu 26,7 $\mathrm{mm}$. Dessa forma, a expansão livre (E) foi estimada em 3,9\%.

Já no corpo de prova compactado (Figura 9), com saturação na pressão de $25 \mathrm{kPa}$, obteve-se uma expansão livre de apenas 1,08\% que, de acordo com Nelson e Miller (1992) não configuraria mais o solo como expansivo.

Vale mencionar que a determinação da expansão livre foi realizada a partir da seguinte expressão (Equação 3):

$$
E=\frac{\Delta H}{H_{0}} x 100
$$

Sendo:

E : expansão livre;

$\Delta \mathbf{H}$ : acréscimo de altura máximo por saturação;

$\mathbf{H}_{\mathbf{0}}$ : altura inicial do corpo de prova antes da saturação.

Dessa forma, para este caso específico, verifica-se que o processo de compactação praticamente anulou o potencial de colapso/expansão do solo.

\section{CONSIDERAÇÕES FINAIS}

A realização do presente estudo permitiu estabelecer as seguintes conclusões:

- Para o caso específico em que trata esse artigo, as amostras de solo estudadas apresentaram comportamentos divergentes de acordo com o tipo de procedimento de ensaio (edométrico simples ou duplo), no entanto, será necessário a realização de um número maior de ensaios em trabalhos futuros para a comprovação, ou não, da mencionada divergência de resultados;
- De acordo com o ensaio edométrico simples o solo estudado na condição natural não apresenta potencial de expansão que o caracterize como solo expansivo;

- Por outro lado, a partir do ensaio edométrico duplo o solo estudado na condição natural pode ser considerado como potencialmente colapsível;

- A partir da realização desse trabalho verificou-se que o processo de compactação mostrou-se uma técnica eficiente para minorar ou mesmo eliminar tanto o potencial de expansão quanto de colapso do solo estudado.

Dessa forma, a realização deste trabalho contribui para a área do conhecimento pois comprova, a partir do estudo de um caso real, que a compactação de solos potencialmente colapsíveis ou expansivos presentes no interior do Ceará, de fato, reduz seus potenciais a níveis aceitáveis para uso como suporte de fundações superficiais de edifícios.

\section{AGRADECIMENTOS}

A CAPES, pelo apoio financeiro pela concessão da bolsa de Mestrado do 1ㅇa autor do artigo e à empresa ROCHABRASIL ENGENHARIA Ltda. pelo apoio na presente pesquisa.

\section{REFERÊNCIAS BIBLIOGRÁFICAS}

AMERICAN ASSOCIATION OF STATE HIGHWAY AND TRANSPORTATION OFFICIALS. AASHTO Materials, Part I, Specifications, Washington, D. C., 1982.

AGNELLI, N.; ALBIERO, J. H. Aspectos físicos, químicos e mecânicos de um solo colapsível, inundado com diferentes líquidos. Revista Brasileira de Geotecnia: Solos e Rochas, Volume 20, № 2. p.16, 1997.

Associação Brasileira de Normas Técnicas (1984). NBR 6458 - Grãos de Pedregulho Retidos na Peneira de 4,8 $\mathrm{mm}$ (Determinação da Massa Específica, da Massa Específica Aparente e da Absorção de Água). Rio de Janeiro, RJ, Brasil.

ASSOCIAÇÃO BRASILEIRA DE NORMAS TÉCNICAS (1984a). NBR 7181 - Solo - Análise Granulométrica. Rio de Janeiro, RJ, Brasil. 
ASSOCIAÇÃO BRASILEIRA DE NORMAS TÉCNICAS (1984b). NBR 7180 - Solo - Determinação do Limite de Plasticidade. Método de Ensaio, Rio de Janeiro, RJ, Brasil.

ASSOCIAÇÃO BRASILEIRA DE NORMAS TÉCNICAS (1984c). NBR 6459 - Solo - Determinação do Limite de Liquidez. Método de EnsaioRio de Janeiro, RJ, Brasil.

ASSOCIAÇÃO BRASILEIRA DE NORMAS TÉCNICAS (1986). NBR 7182 - Solo - Ensaio de Compactação. Método de Ensaio, Rio de Janeiro, RJ, Brasil.

ASSOCIAÇÃO BRASILEIRA DE NORMAS TÉCNICAS (1990). NBR MB 3366 - Solo - Ensaio de Adensamento Unidimensional. Rio de Janeiro, RJ, Brasil. 1990.

CERNICA, J. N. Geotechnical Engineering: Soil Mechanics. New York: John Wiley and Sons, 453p, 1995.

CINTRA, J. C. A. Fundações em solos colapsíveis. São Carlos: Serviço Gráfico da EESC/USP, São Carlos, 116 p, 1998.

CLEMENCE, S. P.; FINBARR, A. O. Design considerations for collapsible soils. Journal of the Geotechnical Engineering Division, ASCE, v. 107, no GT3, p. 305-317, mar. 1981.

CPRM. Diagnóstico do Município de Icó. Programa de Recenseamento de Fontes de Abastecimento por Água Subterrânea. Serviço Geológico do Brasil, 1998.

CPRM. Estudos Hidrogeológicos das Bacias Sedimentares da Região Semi-Árida do Nordeste Brasileiro. Serviço Geológico do Brasil, 2004.

DINIZ, Hélio Nóbile; SANTORO, Jair. A ocorrência de Solos colapsíveis no Bairro Imaculada, em Taubaté, SP: Um Estudo de Caso. In: I Simpósio Brasileiro de Desastres Naturais. Florianópolis. 2004.

DNIT. Manual de Pavimentação. Diretoria de Planejamento e Pesquisa, Coordenação Geral de Estudos e Pesquisa, Instituto de Pesquisas Rodoviárias, Rio de Janeiro, 274 p, 2006.

FERREIRA, S. R. M. Solos Colapsíveis do Nordeste. Geotecnia do Nordeste, Editora Universitária UFPE, pp.365-395. 2005.

GOMES, R. J. Estudo Geotécnico de um Solo Superficial da Cidade de Bragança Paulista - SP. Dissertação de Mestrado. Universidade Estadual de Campinas, 2006.

MASSAD, Faiçal. Obras de Terra: Curso Básico de Geotecnia. Ed. Oficina de Textos, São Paulo, 2a ed., 2010.
MILITITSKY, Jarbas; CONSOLI, Nilo Cesar; SHNAID, Fernando. Patologia das Fundações. Editora Oficina de Textos, 2a edição. 2008.

MOURA, A. S.; SILVA FILHO, F. C. da; DANTAS NETO, S. A. Estudo do Comportamento de Um Solo Silto Arenoso, Não Saturado, do Campus do Itaperi, em Fortaleza-CE. In: VII Simpósio Brasileiro de Solos não Saturados - 29-31 de agosto de 2011, Pirenópolis-GO. pp.377-382. 2011.

NELSON, J.; MILLER, D. J. Expansive Soils: Problems and Practice in Foundation and Pavement Engineering. John Wiley e Sons, Inc., p. 259, 1992.

PINTO, C. Souza. Curso Básico de Mecânica dos Solos, Ed. Oficina de Textos. 3a edição. 2006.

Reginato, A. R; FERRERO, J. C. Collapse Potencial of Soils and Soil Water Chemistry, Proc. In: $8^{\text {Th }}$ ICSMFE, Moscú, vol 22. pp 177-18, 1973.

RICARDO, H. S.; CATALANI, G. Manual Prático de Escavação: terraplanagem e escavação de rocha. 3a ed. Editoa Pini, 2007.

SILVA, J. M. J. Solos Expansivos. Geotecnia do Nordeste, Editora Universitária UFPE, 2005.

SKEMPTON, A. W. The Colloidal Activity of Clays. In: 3rd International Conference on Soil Mechanics and Foundation Engineering, Londres, v.1, p. 57-61, 1953.

VILAR, O. M. ; MACHADO, S. L. ; BUENO, B. S. . Collapse Behavior of a Compacted Lateritic Soil. In: 2 INTERNATIONAL CONFERENCE ON UNSATURATED SOILS, 1998, Beijing. INTERNATIONAL CONFERENCE ON UNSATURATED SOIL, 2. BEIJING - CHINA : INTERNATIONAL ACADEMIC PRESS, 1998. v. 1. p. 173178.

VILAR, O. M. Ensaios de Campo em Solos não Saturados. Anais do III Simpósio Brasileiro de Solos Não Saturados. Rio de Janeiro: Editora Freitas Bastos, v.2, p. 491, 1997. 